\title{
A mais bela alma
}

Guilherme Grané Diniz

\section{Resumo:}

O trabalho busca mostrar através de um conceito de formação como Natalie é a personagem que mais se aproxima desse ideal dentro da obra Os anos de aprendizado de Wilhelm Meister. Realiza-se essa tarefa mostrando primeiramente o surgimento e desenvolvimento desse conceito dentro da obra, contrapondo os aspectos internos e externos dessa formação pela contraposição entre arte e vida. Depois analisamos mais pormenorizadamente o papel do teatro, principalmente de Shakespeare, dentro do contexto do livro. Em ainda mais um passo, passamos a observar em detalhe a formação da interioridade do homem pela análise das "Confissões de uma bela alma". Explanado o funcionamento da formação interior e exterior, resta extrairmos a conclusão sobre o porquê de Natalie ter melhor cumprido este roteiro.

Palavras-chave: Os anos de aprendizado de Wilhelm Meister - Goethe - Formação Natalie - Shakespeare 
A mais bela alma

Os anos de aprendizado de Wilhelm Meister (GOETHE 2009) ${ }^{\mathrm{I}}$ é um romance de formação, nele são mostrados vários personagens que se relacionam com o mundo e são por ele afetados de vários modos diferentes. Isso, laconicamente, é a formação de que se fala. O que queremos explorar neste texto é como a personagem Natalie serve de modelo para esta formação e em que sentido isto se dá. Para tanto, primeiramente explicaremos brevemente o que se entende por formação e romance de formação, de que modo encontramos essa formação dentro da obra de Goethe e porque Natalie é a personagem que melhor atingiu esse ideal.

Por romance de formação entendemos aquele para o qual a questão de como melhor desenvolver as potencialidades do indivíduo, ou então aquele que trata da relação conflituosa do personagem e seu mundo (MAZZARI 20IO, p. 96) é central. Hegel percebe que os anos de aprendizagem, aos quais o título da obra se refere, não são senão a luta no mundo moderno, o aparar de arestas do indivíduo face ao mundo (id. ibid., p. IOO). O relevante é perceber que a formação se dá em duas instâncias, dentro e fora do indivíduo.

No Meister, a questão aparece na carta escrita no terceiro capítulo do quinto livro, por meio da qual ele responde à oferta de Werner de incluí-lo na vida prática de seus negócios, em que o personagem principal formula: "Instruir-me a mim mesmo, tal como sou, tem sido obscuramente meu desejo e minha intenção, desde a infância" (GOETHE 2009, p. 284). Mazzari (I999, p. 72) nota muito bem como isto se insere na tradição da utopia de tempo, fruto de uma ideia iluminista de progresso, o momento utópico aqui se dá no futuro e não propriamente em um outro lugar (topos). Wilhelm em tal passagem expõe porque deseja dedicar-se exclusivamente ao teatro; pois crê que é somente por meio dele que irá formar-se por completo. Um dos aspectos desta formação pode ser belamente compreendido na metáfora de Meister: "De que me serve fabricar um bom ferro, se meu próprio interior está cheio de escórias? E de que me serve também colocar em ordem uma propriedade rural, se comigo mesmo me desavim?" (GOETHE 2009, p. 284). O que se percebe aqui é uma oposição entre interioridade e exterioridade, a atividade burguesa não é compatível com sua formação, ele deve prescindir do "fabricar um bom ferro" para poder livrar-se das escórias que traz dentro de si, fica claro porque Meister recusou o projeto de Werner. Esta oposição é o mote da formação e é por meio dela que se deve pensar como esta pode se dar.

I A partir de agora será referido apenas como Meister. 
Antes de adentrarmos materialmente os modos pelos quais a formação se verifica no seio da obra mais particularmente, devemos perceber que a bildung aqui se pensa sempre no cenário concreto da Alemanha moderna. Não serve considerarmos a formação abstratamente; do mesmo modo que depende das peculiaridades dos indivíduos, ela sempre se dá no mundo real onde vivem os personagens e os homens. É neste sentido que entra a questão da burguesia e nobreza, a qual será eventualmente retomada em outros pontos do texto. Meister é o filho de um comerciante (id. ibid., p. 56) bastante ávido por dinheiro, que justamente por isso tem interesse em ver o filho longe de suas pretensões artísticas (id. ibid., p. 30). Não que ele participe ativamente do afastamento de seu filho da arte que tanto ama, mas reflete o espírito burguês incapaz de ver além da utilidade imediata; não é por menos que uma das primeiras providências do velho Meister após a morte de seu pai foi vender a coleção de arte (id. ibid., p. 56). Este modo de postar-se perante a vida em um primeiro momento parece obstar a formação de Wilhelm (id. ibid., pp. 284-85), já que só o nobre pode se formar pela vida. O burguês só o faz por meio da representação no teatro, já que ali ele pode "ser e parecer tão bem quanto em qualquer outra parte" (id. ibid., p. 286). Esta carta de Wilhelm a seu amigo Werner é um dos pontos centrais da obra e certamente será recuperada na medida em que se fizer necessária.

Como já notamos, Meister afirma que a formação é seu projeto desde a infância, logo, ela é contemporânea à sua relação com o teatro. De fato, o que ele busca é a formação justamente por meio do teatro. O que pretendemos mostrar neste ponto é como essa formação através da arte é insuficiente e falha. De início, é muito importante ressaltar como todas as vezes nas quais o teatro surge na obra ele possui um sentido de incompletude ou insuficiência. Isso se mostra já nas primeiras palavras do livro, ${ }^{2}$ que compara o romance de Meister com Marianne a uma peça de teatro, por sinal, enfadonha. É bastante claro no primeiro livro da obra a tensão entre a paixão de cunho teatral de Wilhelm (id. ibid., p. 70) e as necessidades da vida que impelem Marianne a Norberg, sendo que a primeira é que sai prejudicada (id. ibid., p. 87). Essa mesma incompletude atinge até a derradeira experiência do personagem principal com a arte teatral; a interpretação de Hamlet, que, só ocorrendo uma vez, logo esgotou o interesse que ele tinha pela obra (id. ibid., p. 32I). Além do que, a apresentação da obra shakespeariana perante o público se deu de modo mutilado. Serlo insistiu para que se representasse tão somente o necessário à obra 
(id. ibid., p. 288), com o que Meister após muito relutar assente, escolhendo ele mesmo as partes a serem retiradas. Note-se que o critério de seleção acerca das cenas que deveriam ficar reflete um aspecto muito relevante da própria obra de Shakespeare.

Isto não se dá por acaso ou contingência, o livro aponta para o fato de que tal incompletude tem algo de intrínseco ao teatro. No momento, é necessário perceber a relação entre a arte e o que Hegel chamou de "poesia do coração" (HEGEL 200I, p. I37). No quarto volume de seus cursos de estética, o autor mostra que o romance é o lugar por excelência de um mundo da vida com orientação para a prosa, no qual cabe retomar a poesia "no que diz respeito [...] aos indivíduos e seu destino" (id. ibid., p. I37); o que se nota, portanto, é que esta poesia se refere à individualidade. No contexto dos anos de aprendizado, o teatro possui exatamente esta função, opondo-se à "prosa das relações sociais"; em suma, a arte é o âmbito do indivíduo e sua interioridade. Podemos notar isso quando Meister propõe a Serlo quais cenas de Shakespeare devem ser cortadas.

De início, faz ele uma distinção fundamental dentre as duas vertentes da peça, uma que trata da interioridade e do caráter dos personagens e outra dos acontecimentos que os relacionam entre si. Meister propõe que apenas a segunda pode ser tocada, enquanto que a primeira há de ser mantida em sua totalidade. Isso permite entrever claramente a posição do personagem em relação à arte em geral e ao teatro em particular, o aspecto exterior pode e até mesmo deve ser reduzido ao mínimo necessário para que se dê ênfase aos sujeitos que tomam parte na peça (GOETHE 2009, pp. 289-90). O que propomos aqui é que esta interpretação da obra não é ocasional, ela reflete muito bem o que é o teatro e quais são seus limites; ele pode formar um indivíduo em sua interioridade, mas é incapaz de preencher por completo esta formação do modo como já reiteradamente a descrevemos, como interna e externa.

Antes de retomarmos a análise do papel de Shakespeare nesta obra, cumpre mostrarmos em que medida e de que modo pode se dar a formação de um indivíduo apenas em seu aspecto interior. Para tal, analisaremos agora as "Confissões de uma bela alma", que compõe o sexto livro da obra. Ela inicia após a segunda canção de Mignon (id. ibid., pp. 345-46), a qual serve como um fecho à aventura teatral do protagonista, assim como a primeira canção marca o início de seu envolvimento mais profundo e profissional com o mesmo (id. ibid., p. I5I), ou seja, ela encontra-se no momento posterior àquele predominantemente da interioridade do protagonista, mas não deixa também de integrá-lo, como uma leitura superficial já é capaz de notar. Estamos interessados em mostrar como ela serve de fecho ou resumo para este 
primeiro período do aprendizado de Meister, indicando o que lhe aguardaria se seguisse no caminho da interioridade da arte.

Essas confissões tratam da formação da tia de Natalie (id. ibid., p. 573), desde a infância uma pessoa de saúde frágil que por isso mesmo tinha uma disposição muito maior para a religiosidade e para a reflexão. ${ }^{3}$ Se de início seus interesses se estendiam por arte, religião e ciência, sendo que as duas primeiras estavam fortemente ligadas por meio da arte do barroco tardio, ela logo foi tragada pelo mundo da vida, o qual, note-se, foi introduzido por meio da arte, no caso a dança, fazendo-a ignorar por um momento sua interioridade, para então, traumatizada por suas experiências afetivas com o jovem Narcisse, retomar o caminho original de sua formação, dessa vez com o aspecto quase que somente religioso. É relevante notar também como durante todo o período em que ela viveu "dias e dias sem falar, não ter um pensamento sadio" (id. ibid., p. 353) não foi um tempo de ausência do elemento interior, ele ainda filtrava as impressões recebidas pelo mundo e organizava as experiências vividas. Após essa época de sua vida, ela passou a diminuir seriamente seus laços com o mundo exterior, passando a ter forte orgulho e convicção no caminho que escolhera para si. Nesse tempo conhece seu tio, o qual, mesmo que não a compreendesse inteiramente, mostrava certa inclinação por ela, oferecendo-lhe um cargo como canonisa, a partir do qual ela passou a se relacionar com o mundo, mas sempre de modo ligado a sua religiosidade. A morte de seus pais não faz senão reforçar esse sentimento piedoso, o qual ela buscava alimentar de modo sistemático. Após esses eventos, ela conhece Philo, o qual surge novamente no sentido de reafirmar suas convicções por meio da repulsa do desejo carnal e da filiação às ideias dos Hernutos, grupo religioso pietista. Suprimindo mais alguns acontecimentos menores, chegamos à descoberta de que o tio guiara a educação de seus sobrinhos e sobrinhas, Natalie inclusa, por intermédio das ideias de um tal abade. A referencia à Sociedade da Torre é bastante clara, portanto. Enfim, as confissões encerram-se com mais um testemunho de como a fé e a interioridade permeiam o mundo da vida.

Este relato extenso mas não exaustivo faz-se necessário no sentido de fornecer elementos contextualizados da obra para análise. As semelhanças com a história da formação de Meister até o momento são claras. A introdução à arte e à interioridade por meio de obras de cunho religioso (para ela, o "Hércules Cristão-Alemão" (id. ibid., p. 349), para ele, "Jerusalém

3 Id. ibid. Para economia nas referências, remetemos às páginas 347 a 404 para todos os elementos aqui abordados destas confissões. 
Libertada" (id. ibid., p. 43) e a adaptação do livro I de Samuel, do Antigo Testamento) (id. ibid., p. 30); o modo como esta interioridade conflita com o mundo exterior ao tentar interpretá-lo de acordo com seus princípios (id. ibid., pp. 354-55, dentre outras), o que Meister faz, por exemplo, quando trata com Melina na ocasião de sua fuga (id. ibid., pp. 66-67) passagem na qual lemos um diálogo em que o personagem central afirma ser o teatro uma profissão com "atraentes perspectivas" (id. ibid., p. 67). Outra semelhança se percebe no modo como essa interioridade é justamente o que permite a ambos relacionar-se com o mundo, no caso da mulher em sua função de canonisa (id. ibid., p. 372), para Meister como ator que viaja e conhece novos lugares e pessoas. Notamos enfim o caso de amor frustrado pelas necessidades da vida quanto à tia de Natalie, quando Narcisse não consegue um cargo que o permita sustentar dignamente a ambos (id. ibid., p. 369) e quanto a Meister, quando é preterido por Marianne em troca do burguês Norberg, capaz de lhe dar condições de vida mais vantajosas (id. ibid., pp. 85-86).

As semelhanças que citamos são exemplificativas e vêm no sentido de demonstrar que Meister estava seguindo sua formação exatamente no mesmo caminho que a personagem das "Confissões da bela alma". Seria de se esperar, portanto, que ele em algum momento atingisse o mesmo ponto que ela, ou seja, que seus processos semelhantes formassem pessoas minimamente semelhantes. Isso se verificaria se ao final da obra Meister fosse um homem religioso, confiante no caminho em que seguisse e abandonado a seus impulsos naturais, mas ainda assim temeroso do mundo, ressabiado quanto ao "monstro [que] pode nascer e nutrir-se em cada coração humano" (id. ibid., p. 404). Não é o que ocorre. Como termina a formação de Meister veremos mais adiante, mas podemos antecipar que ela o faz de modo muito diferente do que a de quem se forma apenas segundo sua interioridade. Isso aponta para o fato de que algo mudou na vida de Meister, o momento disso já indicamos, o fim de sua experiência teatral na obra marcada pelo segundo canto de Mignon.

A partir desse momento, pode-se dizer que Meister passou a se formar pela vida. Porém, antes de explorar o que isso significa, é necessário perceber como essa transição se deu. Georg Lukács, em seu ensaio sobre o Meister, ${ }^{4}$ percebe o ponto central da presença de Shakespeare dentro dessa obra. Hamlet é uma peça teatral, parte do mundo da interioridade, contudo o supera em muito, não se contém em seus limites, afinal, Shakespeare é o "grande edu-

4 "Goethe e seu tempo", incluso como posfácio na edição do Meister aqui utilizada. 
cador", ele é capaz de mostrar as personalidades plenamente desenvolvidas (id. ibid., p. 583), é quase como se nele encontrássemos o protótipo dos romances de formação. Mas devemos lembrar, ao longo de todo o texto, tanto nós como Goethe tratamos da formação não apenas de personagens literários, mas de homens reais, de sujeitos que encaram novos desafios a partir da era moderna. Exploraremos melhor essas ideias no sentido de mostrar como é o contato de Meister com Hamlet, que o leva de um modelo de formação artística para uma formação pela vida.

Para tanto, analisaremos a metáfora já clássica do carvalho plantado no vaso. Ela encontra-se formulada no texto da seguinte maneira: "parece-me claro o que Shakespeare pretendeu descrever: uma grande ação imposta a uma alma que não está a altura de tal ação. É neste sentido que vemos a peça cuidadosamente trabalhada. Vemos aqui um carvalho plantado em rico vaso, que não deveria receber em seu seio senão lindas flores; as raízes se estendem, e o vaso se quebra" (id. ibid., p. 224). Ela é empregada no sentido de explicar o desfecho de Hamlet. O indivíduo não foi capaz de suportar o peso de sua tarefa, sucumbindo moralmente no sentido de transformar-se em um homem sarcástico (SHAKESPEARE 2007, p. 68I), sempre com um tom sombrio sobre suas palavras, ${ }^{5}$ culminando em sua morte sem completar sua vingança (id. ibid., p. 7I2). Dito com simplicidade, a metáfora do vaso transmite a ideia de uma ação que o sujeito deve empreender mas não é capaz, o que resulta na necessidade de superação dos limites ou na "quebra" do sujeito. Isso é de suma relevância, na medida em que podemos afirmar existirem reiteradamente na obra "metáforas do vaso", uma miríade de situações nas quais ocorre algo semelhante ao que acabamos de verificar.

A primeira delas é justamente a relação de Meister com o teatro e, particularmente, com a interpretação de Hamlet. Após a entrada do personagem principal na Sociedade da Torre, Serlo afirma que ter saído do teatro foi uma boa escolha, já que Meister foi um ator muito limitado. Existe algo de muito particular nessa crítica, principalmente quando pensamos no trecho em que se diz: "quem só a si mesmo consegue representar não é ator" e, mais a frente, "o senhor representou muito bem o Hamlet e alguns outros papéis para os quais lhe favoreciam seu caráter" (GOETHE 2009, p. 523). Disso se depreende que podemos estabelecer uma relação entre o personagem de Goethe e o de Shakespeare, ambos podem ser vistos como o vaso; o carvalho que Hamlet recebeu já mostramos, o carvalho de Meister é o teatro, para o qual o

5 Tome como exemplo o monólogo ao fim de Shakespeare (2007, p. 699). 
personagem não tem habilidade. A interpretação de Shakespeare é o ponto no qual a experiência do ator com a arte encontra seu fim, foi o romper do vaso. Isso se dá na interpretação dessa obra em particular justamente porque ela é maior que o teatro, esse formato de apresentação é insuficiente para conter o que Hamlet traz. É como se a peça fosse um carvalho, o teatro um recipiente frágil demais para recebê-lo.

As razões pelas quais podemos afirmar que Shakespeare aponta para além do teatro são complexas de se explicar. Podemos sabê-lo por meio do que se diz no Meister em algumas passagens. Apesar disso, esboçaremos aqui uma possível resposta após mostrar como os próprios personagens indicam que Shakespeare é um ponto de inflexão entre teatro e vida. Uma primeira ideia que podemos trabalhar aqui já foi discutida, que Hamlet não cabe no teatro e deve ser cortado, sendo que Meister se convence disso e propõe ele mesmo os cortes a serem feitos. O que nos interessa é como a obra, inclusive fisicamente, ultrapassa "a medida do pessoal, da direção e da mecânica teatral, do tempo, do diálogo e das forças físicas do ator” (id. ibid., p. 289) e não pode ser executada sem prejuízo. Note que o próprio Meister acreditava que se Shakespeare estivesse mais atento às questões de execução, teria realizado esses cortes em sua obra. Fica bastante claro, portanto, como o teatro não é a forma mais adequada para Hamlet. É interessante como nos parece que a leitura de Shakespeare tem muito mais impacto sobre Meister que a interpretação. Por sinal, após a leitura é que nasce o interesse ardente pelo autor, após a interpretação esse interesse se apaga. Isso não é eventual, existe algo na própria ideia de interpretação que faz com que ela seja capaz de voltar os olhos para o mundo da vida e tirá-los de si, que representa apenas a interioridade.

Afinal de contas, é exatamente isso que acontece no próprio Hamlet. A peça de teatro ali interpretada não faz senão abrir os olhos do príncipe para a realidade do mundo e a necessidade de sua intervenção. É por meio dela que o príncipe se convence da necessidade de vingança contra seu tio, posto que ela lhe permite ter segurança de que ele foi o criminoso que matou o rei, seu pai (SHAKESPEARE 2007, pp. 692-93). Ou seja, o acontecimento da interpretação permite a Hamlet enxergar os fatos e perceber que ele deve cumprir a vontade do espectro de vingança, ela tem o condão de revelar verdades sobre o mundo no qual atua. No Meister não ocorre algo diverso, as peças de Shakespare fazem o personagem entender que a formação que ele busca é insatisfatória e só dá conta de um dos aspectos do sujeito.

Schiller (I993, p. 68) é claro no sentido de que Natalie é um modelo para a formação, e o próprio Goethe também nos dá a entender isso, tanto ao mostrar que a tia de Natalie, a bela alma, a admira e até a reconhece como de certo 
modo superior (GOETHE 2009, p. 402), e quando Lothario reconhece ser ela uma alma mais bela que sua tia (id. ibid., p. 573). Daí dizermos ser ela a mais bela alma, o grande exemplo de formação na obra. Isso se dá pelo motivo que já repisamos aqui, porque conseguiu formar-se tanto interior quanto exteriormente, nos modos que mostramos aqui. Note, por exemplo, a passagem já referida onde sua tia fala de sua admiração por ela, que mostra como Natalie era piedosa e generosa, mas além disso ela tinha noção de economia e praticidade, suas doações aos necessitados nunca se davam em pecúnia, mas em utilidades. Schiller também ressalta como Natalie é ao mesmo tempo santa e real, da natureza; ainda na mesma passagem ressalta como na personagem misturam-se o mundo estético com o da vida (GOETHE; SCHILLER I993, p. 68). Esse é o ideal da formação, forma-se pela vida, mas sem descuidar e ignorar da interioridade, sob pena de terminar hipocondríaco e envelhecido como Werner (GOETHE 2009, p. 476). É notável nessa passagem como as mudanças na formação se deram de modos diferentes, de modo a chegarem a se manifestar fisicamente nos personagens. Daqui podemos extrair que a formação de Meister se dá de modo ao menos em parte semelhante ao de Natalie.

A ideia de bela alma foi empregada por Goethe como a de alguém que se formou por meio de sua interioridade. Serlo a completa, ele percebe como a beleza da alma é resultado da bildung, da formação da pessoa. A tia de Natalie é uma bela alma, mas Natalie mesma é uma alma ainda mais bela justamente porque não se limitou a ser alma, seguiu os caminhos da vida e se formou em toda a sua dimensão subjetiva, como um ser humano propriamente moderno. Pode ter parecido despropositado expor o movimento da formação de Meister, já que não era esse o ponto central do trabalho, mas foi necessário para mostrar em detalhe o caminho mais apropriado da formação, certamente seguido à sua própria maneira pela personagem, o qual passa por vicissitudes e contingências até que tenha sido percorrido plenamente.

$\mathrm{O}$ que se quer provar neste último ponto é como o teatro, o aspecto interior do personagem principal, não foi simplesmente abandonado. Por mais que ele não subsista enquanto atividade e atuação, ele ainda se faz presente de algum modo. Nesse sentido é clara a fala de Abbè quando mostra a Meister que "tudo que nos acontece deixa rastros, tudo contribui, ainda que de maneira imperceptível, para nossa formação" (id. ibid., p. 406). O próprio personagem reconhece a verdade dessa afirmação em passagem subsequente (id. ibid., p. 4IO). O aspecto interior da formação permanece mesmo quando a atividade que o constituiu se vai, é nesse sentido que podemos dizer que o teatro não foi totalmente abandonado; por isso que a formação de Meister está indo em um bom sentido; talvez por isso ele se una a Natalie no final, já que ambos 
A mais bela alma

seguem o caminho da formação ideal. Antes de nos despedirmos do leitor, só resta apontar uma possível resposta para de que modo o teatro subsiste, e este parece ser justamente em sua ausência, que se dá particularmente pela obra de Shakespeare, conforme mostrado anteriormente. É pelo teatro que Meister tem acesso ao mundo da vida e não podemos saber se, dadas as circunstâncias nas quais a formação toma lugar, já que ela se dá sempre particular e concretamente, sem o teatro Meister teria se formado de modo tão acertado. Assim, sem o aspecto interior de sua formação e sem a presença do teatro e de Hamlet, é bem possível que Meister jamais tivesse atingido o mundo da vida e essa formação que, como já exposto, parece tão apropriada. O modo pelo qual o teatro se fez ausente, portanto, é tal que ele permanece sempre como a condição prévia para o acesso do personagem principal ao mundo da vida.

Ademais, apenas resta desejarmos a quem nos acompanhou até este ponto uma leitura, senão instrutiva, ao menos agradável.

\section{Referências bibliográficas}

GOETHE, Johann Wolfgang von. Os anos de aprendizado de Wilhelm Meister. São Paulo: Editora 34, 2009. ; SCHILLER, Friedrich. Companheiros de viagem. São Paulo: Nova Alexandria, I993.

MAZZARI, Marcus Vinicius. Labirintos da aprendizagem. São Paulo: Editora 34, 2010. Romance de formação em perspectiva histórica. São Paulo: Ateliê Editorial, I999.

SHAKESPEARE, William. Hamlet. In: The Complete Works of William Shakespeare.

Oxford: Wordsworth, 2007.

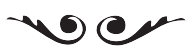

Guilherme Grané Diniz - Graduando em Filosofia pela Universidade de São Paulo.

guilhermegranediniz@gmail.com 